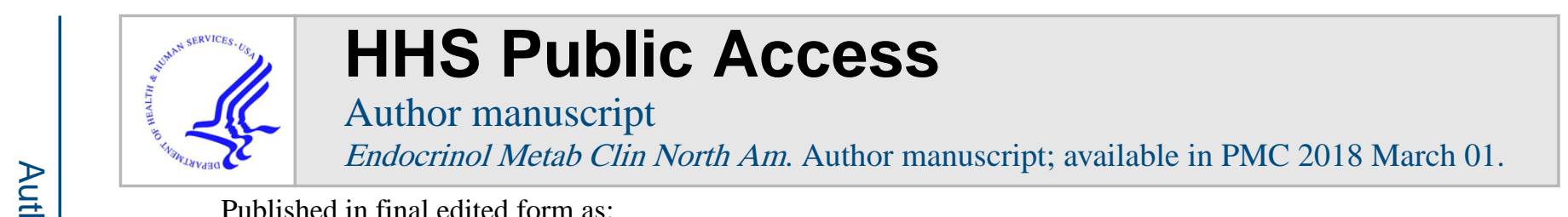

Published in final edited form as:

Endocrinol Metab Clin North Am. 2017 March ; 46(1): 117-133. doi:10.1016/j.ecl.2016.09.007.

\title{
PREMENOPAUSAL OSTEOPOROSIS
}

\author{
Adi Cohen, MD, MHS \\ Associate Professor of Medicine, At Columbia University Medical Center, Division of \\ Endocrinology, Department of Medicine, New York, NY, USA
}

\section{SYNOPSIS}

\begin{abstract}
Most premenopausal women with low trauma fracture(s) or low BMD have a secondary cause of osteoporosis or bone loss. Women who present with unexplained fractures or low BMD should have a thorough clinical and laboratory evaluation to search for known causes of fractures and/or bone loss. Where possible, treatment of the underlying cause should be the focus of management. Premenopausal women with an ongoing cause of bone loss and those who have had, or continue to have, low trauma fractures may require pharmacological intervention. Clinical trials provide evidence of benefits of bisphosphonates and teriparatide for bone mineral density in several types of premenopausal osteoporosis, but studies are small and do not provide evidence regarding fracture risk reduction.
\end{abstract}

\section{Keywords}

Premenopausal women; Secondary causes of osteoporosis; Osteoporosis treatment

\section{Introduction}

Osteoporosis is less common in premenopausal women than in postmenopausal women. However, both fractures and low bone mineral density do occur in the premenopausal years, and young women with these conditions require specialized clinical considerations. This article will review the definition, epidemiology, and potential etiologies of osteoporosis in premenopausal women and will also address recommendations for evaluation as well as potential treatment strategies. The reader is also referred to previously published reviews on this topic ${ }^{1-7}$

Correspondence to: Adi Cohen.

AUTHOR CONTACT INFORMATION: Adi Cohen MD, MHS, Columbia University, College of Physicians \& Surgeons, Department of Medicine, PH8-864, 630 West $168^{\text {th }}$ Street, New York, NY 10032, Telephone: 212-305-7225, ac1044@ columbia.edu DISCLOSURE STATEMENT

Dr. Cohen receives research support from Eli Lilly and Company and Amgen.

Publisher's Disclaimer: This is a PDF file of an unedited manuscript that has been accepted for publication. As a service to our customers we are providing this early version of the manuscript. The manuscript will undergo copyediting, typesetting, and review of the resulting proof before it is published in its final citable form. Please note that during the production process errors may be discovered which could affect the content, and all legal disclaimers that apply to the journal pertain. 


\section{Diagnosis of Osteoporosis in Premenopausal Women}

\section{Premenopausal Fractures}

The diagnosis of osteoporosis in a premenopausal woman is most secure when there is a history of low trauma fracture. A fracture is considered to be low trauma if it is sustained in the setting of trauma equivalent to a fall from a standing height or less. Stress fractures occur in the context of continued skeletal stress and in the absence of a specific traumatic event. Clinical judgment is required to determine whether normal stress on fragile bone or excessive stress on normal bone have led to the pathology. As in all cases of unusual fracture, the diagnosis of osteoporosis should be considered only after osteomalacia (undermineralization due to causes such as severe vitamin D deficiency or hypophosphatemia) and other causes of pathological fracture (eg malignancy, avascular necrosis, fibrous dysplasia, other bone lesion) have been ruled out.

Fractures are substantially less common in premenopausal women than in postmenopausal women ${ }^{8-12}$. However, premenopausal fractures may be an important indicator of underlying poor bone quality and future fracture risk. Data from the Study of Osteoporotic Fractures (SOF) demonstrate that women with a history of premenopausal fracture are 35 percent more likely to fracture during the postmenopausal years compared with women without a history of premenopausal fracture ${ }^{9}$. In cross-sectional study of 1284 postmenopausal women in New Zealand, a history of fracture between ages 20 and 50 was associated with a $74 \%$ increased risk of fracture after age 50 years ${ }^{12}$. In both studies, these relationships persisted after controlling for a number of potential confounding variables. Other studies have reported similar findings 13,14 .

Low trauma fractures in premenopausal women are usually related to known risk factors for bone fragility, called secondary causes of osteoporosis (see below). Low trauma fracture(s) in a premenopausal woman should lead to an evaluation that includes bone mineral density testing and a thorough evaluation for potential secondary causes.

\section{Interpretation of Bone Mineral Density Measurements in Premenopausal Women}

In postmenopausal women, bone mineral density (BMD) assessment by dual energy $\mathrm{x}$-ray absorptiometry (DXA) is a cornerstone of fracture risk prediction models used for therapeutic decision-making because of the wealth of longitudinal observational and interventional studies correlating DXA findings with fracture incidence in this population.

In premenopausal women, cross-sectional studies have reported lower BMD by DXA in those with fractures. Premenopausal women with Colles fractures have been found to have significantly lower BMD at the non-fractured radius ${ }^{15}$, lumbar spine, and femoral neck 16 than controls without fractures. Female military recruits and athletes with stress fractures were also found to have lower BMD than controls ${ }^{17-19}$. However, there are few longitudinal prospective studies relating BMD by DXA to fracture risk in premenopausal women. Because of this, and because fracture rates are much lower in premenopausal than postmenopausal women ${ }^{9,11,12}$, the predictive relationship between BMD and short-term fracture incidence is unclear in premenopausal women. Similarly, the WHO FRAX® tool provides fracture probability only for those aged 40 and above and is intended to be applied 
to postmenopausal women. For these reasons, measurement of BMD by DXA should not be used as the sole guide for diagnosis or treatment of osteoporosis in premenopausal women.

Screening bone mineral density by DXA is not recommended in premenopausal women ${ }^{20}$. Bone mineral density measurement is recommended in young women with a history of low trauma fracture and in those with known causes of bone loss (see Secondary Causes below).

Two organizations have provided guidelines regarding DXA interpretation in premenopausal women.

The International Society for Clinical Densitometry (ISCD) recommends use of BMD Z scores (comparison to age matched norms) rather than $\mathrm{T}$ scores (comparison to premenopausal norms) at the lumbar spine, hip and forearm ${ }^{20}$. A Z score $\leq-2.0$ should be interpreted as "below the expected range for age" and a $\mathrm{Z}$ score $>-2.0$ as "within the expected range for age" 20 . The diagnostic categories of "osteopenia" and "osteoporosis" based solely upon BMD T score should not be applied in premenopausal women, however T scores may be used in the perimenopausal period. The ISCD ${ }^{20}$ and others $1,3,21,22$, have recommended that young, otherwise healthy women should not be diagnosed with osteoporosis solely on the basis of low aBMD by DXA, unless there is a history of fragility fracture or a secondary cause of osteoporosis (see below).

The International Osteoporosis Foundation (IOF) recommends use of $\mathrm{Z}$ score $<-2$ to define low bone mass in children, adolescents, those under 20 years, and some over 20 years in the context of delayed puberty. In contrast to ISCD, the IOF recommends use of T scores in those aged 20-50 years and suggests use of T score $<-2.5$ to define osteoporosis, particularly in those with known secondary causes or in the context of low trauma fractures that provide evidence of bone fragility ${ }^{7}$.

Idiopathic low bone mineral density-Women with low BMD without a history of adult low trauma fracture and without a known cause can be said to have idiopathic low bone density ${ }^{23}$. Based upon current recommendations, such women should not be diagnosed with "osteoporosis".

However, three dimensional bone imaging and transiliac bone biopsy studies preformed by our group have shown that healthy, normally menstruating, premenopausal women with unexplained low BMD and no fractures (idiopathic low BMD) have micro-architectural disruption and decreased estimated bone strength that is similar to a comparable cohort of premenopausal women with idiopathic low trauma fractures, even after correcting for bone size $23-25$. This finding is also supported by data from a group of premenopausal women with constitutional thinness (very low BMI, normal menses and no known systemic disease), who were found to have low BMD, smaller bone size, and decreased estimated breaking strength in comparison to normal women ${ }^{26}$. These studies are limited by their small sample size as well as the possibility of referral/ascertainment bias. Although these results may not be generalizable to all premenopausal women with low aBMD by DXA, they suggest that very low BMD may represent a pre-symptomatic phase of osteoporosis in premenopausal women. 
It should be noted that, even though the currently available data suggest that those young women with idiopathic low bone density and no fracture history are likely to have abnormal bone microarchitecture that is consistent with osteoporosis, this does not mean that such a finding should be used to make therapeutic decisions in premenopausal women as in postmenopausal women. This is because (1) currently available data do not allow us to use BMD by DXA to predict fracture risk in premenopausal women, (2) fracture risk depends greatly on age and (3) few studies have addressed risks and benefits of osteoporosis medications in premenopausal women. Risks and benefits of osteoporosis medications are likely to differ in premenopausal women compared to postmenopausal women.

\section{Special Considerations Required for Interpretation of BMD Results in Premenopausal Women}

Dynamics of Peak BMD Accrual-BMD in premenopausal women depends primarily upon achievement of peak bone mass. Attainment of peak bone mass varies according to gender ${ }^{27,28}$, ethnicity ${ }^{29}$, body size, menarchal age ${ }^{30,31}$ and region of bone. In healthy girls, the peak period of bone mass accrual occurs between ages 11 and $14^{32}$, and the rate of bone mass accrual slows dramatically by approximately 2 years after menarche ${ }^{27}$. Although at least 90 percent of peak bone mass is acquired by the late teen years ${ }^{32-34}$, studies have documented small additional gains between the ages of 20 and $29^{35}$. Moreover, populationbased, cross-sectional studies suggest that the timing of peak bone mass accrual may be site specific $^{27}$, with women reaching peak bone mass at the proximal femur in their 20 s and at the spine and forearm around age $30^{36}$. When interpreting BMD measurements in premenopausal women, the possibility that peak bone mass has not yet been achieved must always be considered.

Low BMD in a premenopausal woman may result from the attainment of a peak bone mass that is below average due to genetic predisposition, illnesses or medications that negatively impact bone density accrual. The factors responsible for the attainment of low peak bone mass may, or may not, remain active or measurable at the time of the evaluation. Low BMD in a premenopausal woman that is related to genetic factors that determine peak bone mass or to a previously active secondary cause may not be associated with ongoing bone loss, but could be associated with abnormal bone quality (see Idiopathic Low Bone Mineral Density, above).

Physiologic changes associated with pregnancy and lactation-Changes in bone mass in association with both pregnancy and lactation have been reported in several studies. At the lumbar spine, longitudinal studies document losses of 3-5\% over a pregnancy and 3$10 \%$ over a 6 month period of lactation ${ }^{37}$, with recovery of bone mass demonstrated over $6-$ 12 months, thereafter, even in the setting of continued lactation ${ }^{38,39}$. At the hip, bone loss of $2-4 \%$ has been documented over 6 months of lactation ${ }^{37}$. The amount of bone loss during lactation is directly associated with longer durations of lactation and postpartum amenorrhea ${ }^{38-41}$. Both human and rodent studies suggest that patterns of recovery of bone mass after weaning are site-specific, with full recovery at the spine, but only partial recovery at the femur $40,42,43$. However, to date longitudinal studies of BMD recovery in humans 
extend to 12-20 months postpartum. Longer duration of follow up may be required to document the true degree of recovery.

The majority of epidemiological studies in humans suggest that the net effect of the loss and regain of bone mass during and after lactation does not affect postmenopausal bone mass or long-term fracture risk. ${ }^{44-46}$. However, other studies show that multiparity and longer periods of lactation are associated with decreased bone mineralization ${ }^{47-52}$. Additionally, studies performed in Turkey, China, and Mexico, suggest that there may be an impact of lactation history on postmenopausal BMD in some populations $48,53,54$. Differences in population age, stature, parity, socioeconomic conditions, study duration and design, analysis techniques and covariates included must be taken into account when interpreting these differing results.

Because of these physiologic bone mass changes associated with reproduction, interpretation of BMD results in premenopausal women must take into account the timing of any recent pregnancy or lactation. Based on available data, BMD at the lumbar spine is likely to have returned to that individual's premenopausal baseline by 12 months post-weaning 40 .

Pregnancy and Lactation Associated Osteoporosis (PLO)—In some women, premenopausal osteoporosis may first present with low trauma fracture(s), usually at trabecular sites such as the vertebrae, occurring in the last trimester of pregnancy or during lactation $55,56.41,57$ Given the physiologic bone mass changes described above, pregnancy and lactation may represent particularly vulnerable times for the premenopausal woman's skeleton, particularly if low bone mineral density is present before pregnancy.

However, premenopausal fractures, including those associated with pregnancy and lactation, remain quite rare, suggesting that additional factors contribute to bone fragility in women who present with fractures during this time. Women with low trauma fractures sustained during pregnancy and/or lactation require the same thorough evaluation for secondary causes as do young women with fractures that are not associated with reproductive events. We have included women with PLO, in whom no cause is found after extensive evaluation, in cohorts defined to have idiopathic osteoporosis ${ }^{23,58}$.

\section{Secondary Causes of Osteoporosis in Premenopausal Women}

Most premenopausal women with low-trauma fractures or low BMD have an underlying disorder or medication exposure that has interfered with bone mass accrual during adolescence and/or has caused excessive bone loss after reaching peak bone mass. In a population study from Olmstead County, Minnesota, 90\% of men and women aged 20-44 with osteoporotic fractures and low BMD were found to have a secondary cause ${ }^{59}$. In contrast, several case series of young women with osteoporosis from tertiary centers report that only $50-60 \%$ have secondary causes ${ }^{60-62}$, likely reflecting referral bias.

Potential secondary causes are listed in Box 1 and fall into several broad categories: estrogen deficiency, inflammatory diseases, collagen disorders, gastrointestinal diseases, and glucocorticoids and other medication exposures. Many diseases of childhood and young adulthood (e.g. gastrointestinal diseases, inflammatory diseases) lead to osteoporosis 
through multifactorial mechanisms involving the combined effects of malnutrition, systemic inflammation, estrogen deficiency/delayed puberty, and medication effects.

\section{Box 1}

\section{Secondary causes of osteoporosis in premenopausal women}

- Any childhood disease that has affected puberty and/or skeletal development

- $\quad$ Premenopausal amenorrhea (eg pituitary diseases, medications, exercise induced amenorrhea)

- $\quad$ Anorexia nervosa

- Cushing syndrome

- Hyperthyroidism

- $\quad$ Primary hyperparathyroidism

- Vitamin D, calcium, and/or other nutrient deficiency

- Gastrointestinal malabsorption (celiac disease, inflammatory bowel disease, cystic fibrosis, postoperative states)

- $\quad$ Rheumatoid arthritis, SLE, other inflammatory conditions

- $\quad$ Connective tissue diseases, eg.

- $\quad$ Osteogenesis imperfecta

- $\quad$ Marfan syndrome

- $\quad$ Ehlers Danlos Syndrome

- $\quad$ Diabetes (Types 1 and 2)

- $\quad$ Renal disease

- $\quad$ Liver disease

- $\quad$ Hypercalciuria

- $\quad$ Alcoholism

- Other rare diseases, including mastocytosis, Gaucher disease, hemochromatosis, hypophosphatasia

Medications (some have not been studied in premenopausal populations)

- $\quad$ Glucocorticoids

- Immunosuppressants (eg cyclosporine)

- $\quad$ Antiepileptic drugs (particularly cytochrome P450 inducers such as phenytoin, carbamazepine)

- $\quad$ Cancer chemotherapy

- $\quad$ GnRH agonists (when used to suppress ovulation) 
- $\quad$ Depo medroxyprogesterone acetate (DepoProvera)

- Heparin

- $\quad$ Other medications with probable relationships to osteoporosis: proton pump inhibitors, selective serotonin reuptake inhibitors, low molecular weight heparin.

The main goal of the evaluation of a premenopausal woman with low-trauma fractures or low BMD is to identify any secondary cause, and to institute specific treatment for that cause if it is indicated. Correction or treatment of several of these conditions, including anorexia nervosa ${ }^{63}$, estrogen deficiency, hypercalciuria ${ }^{64}$, celiac disease ${ }^{65-67}$, Crohn disease ${ }^{68}$, endogenous and iatrogenic hypercortisolism and hyperparathyroidism ${ }^{69}$, has been associated with measureable BMD improvement in some populations, although some have not been specifically studied in premenopausal women.

\section{Evaluation of Premenopausal Women with Low Trauma Fracture and/or Low BMD}

Many secondary causes can be identified by a detailed history and physical examination.

Medical history should include information on:

- $\quad$ adult and childhood fractures

- $\quad$ adult and childhood illnesses and medication exposures

- $\quad$ menstrual history

- timing of recent pregnancy or lactation

- $\quad$ dieting and exercise behavior

- $\quad$ gastrointestinal symptoms

- $\quad$ nephrolithiasis

- family history of osteoporosis and/or nephrolithiasis

Physical examination should seek signs of:

- nutritional deficiency or eating disorder

- $\quad$ Cushing syndrome

- $\quad$ thyroid hormone excess

- $\quad$ connective tissue disorders (eg osteogenesis imperfecta, Ehlers Danlos syndrome, Marfan syndrome),

- $\quad$ inflammatory conditions (eg rheumatoid arthritis, SLE)

Laboratory evaluation may target hormonal, calcium metabolism, or gastrointestinal disorders. Recommendations for an initial laboratory evaluation and a more extensive evaluation are given in Box 2. 
Box 2

\section{Laboratory Evaluation}

Initial Laboratory Evaluation

- $\quad$ Complete blood count

- Electrolytes, renal function

- $\quad$ Serum calcium, phosphate

- $\quad$ Serum albumin, transaminases, total alkaline phosphatase

- $\quad$ Serum TSH

- $\quad$ Serum 25-hydroxyvitamin D

- $\quad$ PTH

- 24 hour urine for calcium and creatinine

\section{Additional Laboratory Evaluation}

- $\quad$ Estradiol, LH, FSH, prolactin

- Screening for Cushing syndrome: 24 hour urine for free cortisol (or dexamethasone suppression test)

- $\quad$ Celiac screen (serologies)

- $\quad$ Serum/urine protein electrophoresis

- $\quad$ ESR or CRP

- $\quad$ Vitamin A/retinol level

- Specific testing for other rare conditions (eg mastocytosis, Gaucher disease, hypophosphatasia, hemochromatosis)

- If genetic diseases such as Gaucher disease, hypophosphatasia or osteogenesis imperfecta are considered, genetic testing may be pursued

- $\quad$ Bone turnover markers

- Transiliac crest bone biopsy

The laboratory evaluation should aim to identify conditions such as:

- $\quad$ vitamin $\mathrm{D}$ and/or calcium deficiency (and laboratory evidence that may distinguish osteomalacia from osteoporosis)

- $\quad$ hyperthyroidism

- $\quad$ hyperparathyroidism

- Cushing syndrome

- $\quad$ early menopause 
- $\quad$ renal or liver disease

- $\quad$ celiac disease and other forms of malabsorption

- $\quad$ idiopathic hypercalciuria.

Utility of markers of bone turnover and bone biopsy-Bone turnover markers may be measured with the goal of distinguishing those likely to have stable BMD from those with an ongoing process of bone loss, who may have a higher short-term risk of fracture. Those with elevated bone turnover markers may also be more likely to have a diagnosable secondary cause. However, bone turnover markers also increase after a fracture, and, when bone turnover markers are assessed in women during very early adulthood, they may be elevated as a result of the active bone accrual occurring in that individual, and may not reflect a process of bone loss.

Transiliac crest bone biopsy after double tetracycline labeling may be useful in certain clinical scenarios when it is necessary to examine bone remodeling, rule out osteomalacia, differentiate between different types of renal osteodystrophy, or complete an examination for rare secondary causes.

Idiopathic Osteoporosis-In some cases of low trauma fracture in premenopausal women, no known secondary cause can be found after extensive evaluation. These women are said to have idiopathic osteoporosis (IOP). Based on current guidelines, the term IOP applies only to those with a history of low trauma fractures, and not to those with low BMD and no history of fractures. That being said, multiple prior studies describing and examining mechanisms of idiopathic osteoporosis in women and men have included both those with fractures and those with low BMD alone.

Several recent publications have described the bone structural and remodeling characteristics of this group. In studies utilizing central quantitative $\mathrm{CT}$, peripheral high-resolution $\mathrm{CT}$, and microCT of transiliac bone biopsy samples, our group has demonstrated markedly thinner cortices, fewer, thinner, widely separated and heterogeneously distributed trabeculae, and lower estimated stiffness in IOP women compared to normal controls. Studies of biochemical and bone remodeling characteristics suggest that the pathogenesis of IOP is heterogeneous, with some women exhibiting evidence of low bone turnover while others have evidence of high bone turnover. Pathogenesis is likely to be diverse; etiologies including excess urinary calcium excretion and IGF-1 axis abnormalities have been implicated $^{23,70}$.

\section{Treatment Consideration for Premenopausal Women with Low Trauma Fractures and/or Low BMD}

For all patients, it is appropriate to recommend adequate weightbearing exercise ${ }^{71}$, nutrition, calcium and vitamin $\mathrm{D}$, as well as lifestyle modifications such as smoking cessation and avoidance of excess alcohol. Current guidelines from the Institute of Medicine ${ }^{72}$ recommend $1000 \mathrm{mg}$ of calcium and $600 \mathrm{IU}$ of vitamin D for premenopausal women. These recommendations could be tailored to the individual based upon evaluation of calcium 
metabolism. Exercise recommendations must also be tailored to the individual patient, since excessive exercise in premenopausal women may lead to weight loss and/or hypothalamic amenorrhea, exacerbating low bone density.

\section{Medications}

Combination oral contraceptives-Use of oral contraceptives to replace estrogen in those who are estrogen deficient may have beneficial effects on bone mass ${ }^{73-75}$, although oral reproductive hormone replacement has been shown to be insufficient for the treatment of osteoporosis in anorexia nervosa, a more complex condition ${ }^{63,74,76}$.

In contrast, the majority of studies of oral contraceptives in healthy premenopausal women without pre-existing estrogen deficiency show no effect of oral contraceptives on bone mass ${ }^{74,77,78}$. Some studies have also documented an adverse effect of low dose $(<30 \mathrm{mcg}$ ethinyl estradiol) oral contraceptives on bone mass in very young women/adolescents ${ }^{79-81}$. Based on available data, the effects of oral contraceptives on fracture risk is unclear ${ }^{77}$.

Selective estrogen receptor modulators-Selective estrogen receptor modulators (SERMS), such as raloxifene and tamoxifen, should not be used to treat bone loss in menstruating women since they block estrogen action on bone and lead to further bone loss 82,83 .

Bisphosphonates-Bisphosphonates have been shown to improve BMD or prevent bone loss in young adults with several conditions, including pregnancy and lactation associated fractures, breast cancer therapy, glucocorticoid therapy, anorexia nervosa, cystic fibrosis and thallessemia ${ }^{55,84-92}$; in some cases, premenopausal women were studied specifically 55,84-88,91,92. Two oral bisphosphonates, alendronate and risedronate, have been approved by the United States Food and Drug Administration (US FDA) for use in premenopausal women receiving glucocorticoids. However, even though trials show favourable short-term BMD outcomes, fracture data are rarely available and long-term risks in premenopausal women are unknown.

Bisphosphonates carry a Category $\mathrm{C}$ rating for safety in pregnancy from the US FDA because they accumulate in the skeleton, cross the placenta and accumulate in the fetal skeleton in a rat model, and have been reported to cause toxic effects in pregnant rats ${ }^{93}$. Although the majority of published case reports have documented no adverse maternal and fetal outcomes ${ }^{55,94-96}$, effective contraception should be encouraged during bisphosphonate use, and it should be kept in mind that there is also the potential for adverse effects after stopping bisphosphonates, since they remain in the skeleton for years.

The choice of bisphosphonates in younger women must also take into account our increasing concerns about the potential risks of long-term use of these agents 97,98 . In young women, plans for duration of bisphosphonate use must be discussed as part of the process of initiation of this therapy, and the goal should be for the shortest possible duration of bisphosphonate use. 
Denosumab-Denosumab is currently approved for the treatment of osteoporosis in postmenopausal women and men at high risk for fracture. Although denosumab may have some advantages in premenopausal populations because of its shorter half-life relative to bisphosphonates and lack of skeletal accumulation, the efficacy and safety of this medication have not been defined in premenopausal women. Denosumab, as marketed for osteoporosis, has been assigned a designation of pregnancy category $\mathrm{X}$; animal studies indicate that denosumab may cause fetal harm.

Teriparatide or PTH(1-34)-Teriparatide or PTH (1-34) have been used successfully in clinical trials to prevent bone loss or increase BMD in premenopausal women on gonadotropin-releasing hormone $(\mathrm{GnRH})$ agonists for the treatment of endometriosis ${ }^{99}$, in premenopausal women taking glucocorticoids ${ }^{100,101}$, in premenopausal women with idiopathic osteoporosis ${ }^{102,103}$, and in those with anorexia nervosa ${ }^{104}$. Additionally, a case series documented benefit in pregnancy-associated osteoporosis ${ }^{105}$. All of the studies described above were limited in terms of sample size, and were not large enough to examine fracture risk reduction. In premenopausal women, FDA approval for use of teriparatide is currently encompassed under the FDA approval for the treatment of those with osteoporosis associated with sustained systemic glucocorticoid therapy at high risk for fracture.

Because the long-term effects of teriparatide in young women are not known, use of this medication should be reserved for those at highest risk for fracture or those who are experiencing recurrent fractures. In young women less than 25 years of age, documentation of fused epiphyses is recommended prior to consideration of teriparatide treatment.

Few data are available to guide treatment options for premenopausal women after teriparatide cessation. One study documented BMD gain in premenopausal women who resumed menses after cessation of both long acting GnRH analog and PTH(1-34) ${ }^{106}$. However, in a study of 13 premenopausal women with idiopathic osteoporosis and normal gonadal function followed for $2.0 \pm 0.6$ years after teriparatide cessation, BMD declined $4.2 \pm 3.9 \%$ at the spine and remained stable at the hip ${ }^{107}$. This finding suggests that women with IOP will require antiresorptive treatment to prevent bone loss after teriparatide.

\section{Specific Clinical Situations}

Idiopathic Low Bone Mineral Density-In premenopausal women with isolated low BMD, no fractures, and no known secondary cause after thorough evaluation, pharmacological therapy is rarely justified. Although these women may have bone microarchitectural abnormalities underlying their low $\mathrm{BMD}^{23,24}$, they are expected to have stable $\mathrm{BMD}^{108}$, and a low short-term risk of fracture. BMD should be measured at one to two-year intervals to identify women with declining BMD. Evidence of declining BMD in a premenopausal woman should lead to continued evaluation for secondary causes, and, in rare cases, consideration of therapeutic options.

\section{Premenopausal women with idiopathic osteoporosis defined based upon}

fracture history-In premenopausal women with a history of low trauma fracture, and no known cause found after extensive evaluation, the use of medications to decrease fracture 
risk could be considered on a case-by-case basis. Fracture location and frequency as well as BMD trajectory should help to guide treatment decisions.

Few data are available to delineate the specific risks or benefits of medications for osteoporosis in women with IOP.

In a study of 9 women with pregnancy and lactation associated vertebral fractures, bisphosphonate treatment over a median of 24 months was associated with substantial BMD gains ${ }^{55}$. However, since bone density is expected to increase postpartum and after weaning in normal women, and there was no untreated control group, it is not clear to what extent bisphosphonate use provided an incremental benefit for these patients.

In an observational study of 21 premenopausal women with IOP, teriparatide 20 mcg daily over 24 months led to BMD increases of $10.8 \%$ at the lumbar spine and $6.2 \%$ at the total hip ${ }^{109}$. However, among this unique cohort, a small subset with very low baseline bone turnover had little or no increase in BMD on this medication 109,110 .

\section{Premenopausal women with fractures or low BMD related to known}

secondary causes-In premenopausal women with low BMD or low trauma fractures and a known secondary cause of osteoporosis, the first goal of management should be to address the underlying cause. Bone density benefits have been shown in the context of intervention for several such secondary causes in premenopausal women:

- $\quad$ Estrogen replacement for those with estrogen deficiency ${ }^{73-75}$

- Discontinuation of medications, for example depot medroxyprogesterone acetate (Depo Provera) ${ }^{111,112}$

- $\quad$ Gluten free diet for celiac disease ${ }^{65-67}$

- Nutritional rehabilitation and weight gain for anorexia nervosa 63

- $\quad$ Parathyroidectomy for primary hyperparathyroidism ${ }^{69}$.

Although thiazides are used for idiopathic hypercalciuria, and appear to have beneficial effects on BMD in men ${ }^{64}$, few data are available in young women.

Continuing or severe effects of the secondary cause may lead to a necessity for pharmacological therapy. Options for treatment are reviewed above.

\section{Glucocorticoid Induced Osteoporosis: Specific Considerations in}

Premenopausal Women-Combination estrogen/progestin contraceptives can be considered (if not contraindicated) in premenopausal women with amenorrhea who are or will be treated with glucocorticoids. Alendronate, risedronate and teriparatide have been approved by the United States Food and Drug Administration (US FDA) for use in women (including premenopausal women) receiving glucocorticoids. However, relatively few premenopausal women participated in the relevant large registration trials for bisphosphonates and teriparatide in glucocorticoid-induced osteoporosis and none of the premenopausal women in those trials fractured ${ }^{100,113-115}$. 
Guidelines from the American College of Rheumatology suggest that bisphosphonates or teriparatide could be considered for premenopausal women of childbearing potential with a history of fragility fracture, if there is glucocorticoid exposure of at least $7.5 \mathrm{mg}$ of prednisone or equivalent per day for $\geq 3$ months ${ }^{116}$.

A study comparing teriparatide and alendronate for glucocorticoid-induced osteoporosis included some premenopausal women. Overall, teriparatide was associated with significantly greater increases in lumbar spine and total hip BMD and resulted in significantly fewer incident vertebral fractures than alendronate ${ }^{101}$. The BMD responses were similar in premenopausal women as in men and postmenopausal women, but no fractures occurred in either premenopausal group ${ }^{100}$.

\section{Summary}

Most premenopausal women with low trauma fracture(s) or low BMD have a secondary cause of osteoporosis or bone loss. Women who present with unexplained fractures or low BMD should have a thorough clinical and laboratory evaluation to search for known causes of fractures and/or bone loss. Where possible, treatment of the underlying cause should be the focus of management. Premenopausal women with an ongoing cause of bone loss and those who have had, or continue to have, low trauma fractures may require pharmacological intervention. Clinical trials provide evidence of benefits of bisphosphonates and teriparatide for bone mineral density in several types of premenopausal osteoporosis, but studies are small and do not provide evidence regarding fracture risk reduction.

\section{References}

1. Gourlay ML, Brown SA. Clinical considerations in premenopausal osteoporosis. Arch Intern Med. 2004; 164:603-14. [PubMed: 15037488]

2. Khan AA, Syed Z. Bone densitometry in premenopausal women: synthesis and review. J Clin Densitom. 2004; 7:85-92. [PubMed: 14742892]

3. Leib ES. Treatment of low bone mass in premenopausal women: when may it be appropriate? Curr Osteoporos Rep. 2005; 3:13-8. [PubMed: 16036096]

4. Abraham A, Cohen A, Shane E. Premenopausal bone health: osteoporosis in premenopausal women. Clinical obstetrics and gynecology. 2013; 56:722-9. [PubMed: 24022503]

5. Cohen A, Shane E. Evaluation and management of the premenopausal woman with low BMD. Curr Osteoporos Rep. 2013; 11:276-85. [PubMed: 24091896]

6. Cohen, A. Premenopausal Osteoporosis. In: Marcus, R.Cauley, J.Dempster, D.Feldman, D., Luckey, MM., editors. Osteoporosis. 4. Philadelphia, PA: Elsevier; 2013.

7. Ferrari S, Bianchi ML, Eisman JA, et al. Osteoporosis in young adults: pathophysiology, diagnosis, and management. Osteoporos Int. 2012

8. Hui SL, Slemenda CW, Johnston CC Jr. Age and bone mass as predictors of fracture in a prospective study. J Clin Invest. 1988; 81:1804-9. [PubMed: 3384952]

9. Hosmer WD, Genant HK, Browner WS. Fractures before menopause: a red flag for physicians. Osteoporos Int. 2002; 13:337-41. [PubMed: 12030549]

10. Melton LJ 3rd, Amadio PC, Crowson CS, O'Fallon WM. Long-term trends in the incidence of distal forearm fractures. Osteoporos Int. 1998; 8:341-8. [PubMed: 10024904]

11. Thompson PW, Taylor J, Dawson A. The annual incidence and seasonal variation of fractures of the distal radius in men and women over 25 years in Dorset, UK. Injury. 2004; 35:462-6. [PubMed: 15081322] 
12. Wu F, Mason B, Horne A, et al. Fractures between the ages of 20 and 50 years increase women's risk of subsequent fractures. Arch Intern Med. 2002; 162:33-6. [PubMed: 11784217]

13. Honkanen R, Tuppurainen M, Kroger H, Alhava E, Puntila E. Associations of early premenopausal fractures with subsequent fractures vary by sites and mechanisms of fractures. Calcif Tissue Int. 1997; 60:327-31. [PubMed: 9075627]

14. Rothberg AD, Matshidze PK. Perimenopausal wrist fracture--an opportunity for prevention and management of osteoporosis. S Afr Med J. 2000; 90:1121-4. [PubMed: 11196034]

15. Wigderowitz CA, Cunningham T, Rowley DI, Mole PA, Paterson CR. Peripheral bone mineral density in patients with distal radial fractures. J Bone Joint Surg Br. 2003; 85:423-5. [PubMed: 12729122]

16. Hung LK, Wu HT, Leung PC, Qin L. Low BMD is a risk factor for low-energy Colles' fractures in women before and after menopause. Clin Orthop Relat Res. 2005:219-25.

17. Lappe J, Davies K, Recker R, Heaney R. Quantitative ultrasound: use in screening for susceptibility to stress fractures in female army recruits. J Bone Miner Res. 2005; 20:571-8. [PubMed: 15765175]

18. Lauder TD, Dixit S, Pezzin LE, Williams MV, Campbell CS, Davis GD. The relation between stress fractures and bone mineral density: evidence from active-duty Army women. Arch Phys Med Rehabil. 2000; 81:73-9. [PubMed: 10638880]

19. Myburgh KH, Hutchins J, Fataar AB, Hough SF, Noakes TD. Low bone density is an etiologic factor for stress fractures in athletes. Ann Intern Med. 1990; 113:754-9. [PubMed: 1978620]

20. Lewiecki EM, Gordon CM, Baim S, et al. International Society for Clinical Densitometry 2007 Adult and Pediatric Official Positions. Bone. 2008; 43:1115-21. [PubMed: 18793764]

21. Licata AA. "Does she or doesn't she...have osteoporosis?" The use and abuse of bone densitometry. Endocr Pract. 2000; 6:336-7. [PubMed: 11242614]

22. Lindsay R. Bone mass measurement for premenopausal women. Osteoporos Int. 1994; 4(Suppl 1): 39-41. [PubMed: 8081057]

23. Cohen A, Dempster D, Recker R, et al. Abnormal Bone Microarchitecture and Evidence of Osteoblast Dysfunction in Premenopausal Women with Idiopathic Osteoporosis. J Clin Endocrinol Metab. 2011; 96:3095. [PubMed: 21832117]

24. Cohen A, Liu XS, Stein EM, et al. Bone microarchitecture and stiffness in premenopausal women with idiopathic osteoporosis. J Clin Endocrinol Metab. 2009; 94:4351-60. [PubMed: 19837923]

25. Cohen A, Lang TF, McMahon DJ, et al. Central QCT Reveals Lower Volumetric BMD and Stiffness in Premenopausal Women with Idiopathic Osteoporosis, Regardless of Fracture History. J Clin Endocrinol Metab. 2012 In Press.

26. Galusca B, Zouch M, Germain N, et al. Constitutional thinness: unusual human phenotype of low bone quality. J Clin Endocrinol Metab. 2008; 93:110-7. [PubMed: 17956951]

27. Bonjour JP, Theintz G, Buchs B, Slosman D, Rizzoli R. Critical years and stages of puberty for spinal and femoral bone mass accumulation during adolescence. J Clin Endocrinol Metab. 1991; 73:555-63. [PubMed: 1874933]

28. Nguyen TV, Maynard LM, Towne B, et al. Sex differences in bone mass acquisition during growth: the Fels Longitudinal Study. J Clin Densitom. 2001; 4:147-57. [PubMed: 11477308]

29. Walker MD, Babbar R, Opotowsky AR, et al. A referent bone mineral density database for Chinese American women. Osteoporos Int. 2006; 17:878-87. [PubMed: 16538554]

30. Chevalley T, Rizzoli R, Hans D, Ferrari S, Bonjour JP. Interaction between calcium intake and menarcheal age on bone mass gain: an eight-year follow-up study from prepuberty to postmenarche. J Clin Endocrinol Metab. 2005; 90:44-51. [PubMed: 15507508]

31. Rosenthal DI, Mayo-Smith W, Hayes CW, et al. Age and bone mass in premenopausal women. J Bone Miner Res. 1989; 4:533-8. [PubMed: 2816502]

32. Theintz G, Buchs B, Rizzoli R, et al. Longitudinal monitoring of bone mass accumulation in healthy adolescents: evidence for a marked reduction after 16 years of age at the levels of lumbar spine and femoral neck in female subjects. J Clin Endocrinol Metab. 1992; 75:1060-5. [PubMed: 1400871] 
33. Bachrach LK, Hastie T, Wang MC, Narasimhan B, Marcus R. Bone mineral acquisition in healthy Asian, Hispanic, black, and Caucasian youth: a longitudinal study. J Clin Endocrinol Metab. 1999; 84:4702-12. [PubMed: 10599739]

34. Bailey DA, McKay HA, Mirwald RL, Crocker PR, Faulkner RA. A six-year longitudinal study of the relationship of physical activity to bone mineral accrual in growing children: the university of Saskatchewan bone mineral accrual study. J Bone Miner Res. 1999; 14:1672-9. [PubMed: 10491214]

35. Recker RR, Davies KM, Hinders SM, Heaney RP, Stegman MR, Kimmel DB. Bone gain in young adult women. Jama. 1992; 268:2403-8. [PubMed: 1404797]

36. Lofman O, Larsson L, Toss G. Bone mineral density in diagnosis of osteoporosis: reference population, definition of peak bone mass, and measured site determine prevalence. J Clin Densitom. 2000; 3:177-86. [PubMed: 10871911]

37. Karlsson MK, Ahlborg HG, Karlsson C. Maternity and bone mineral density. Acta Orthop. 2005; 76:2-13. [PubMed: 15788303]

38. Karlsson C, Obrant KJ, Karlsson M. Pregnancy and lactation confer reversible bone loss in humans. Osteoporos Int. 2001; 12:828-34. [PubMed: 11716185]

39. Sowers M, Corton G, Shapiro B, et al. Changes in bone density with lactation. Jama. 1993; 269:3130-5. [PubMed: 8505816]

40. Kolthoff N, Eiken P, Kristensen B, Nielsen SP. Bone mineral changes during pregnancy and lactation: a longitudinal cohort study. Clin Sci (Lond). 1998; 94:405-12. [PubMed: 9640346]

41. Kovacs CS. Maternal Mineral and Bone Metabolism During Pregnancy, Lactation, and PostWeaning Recovery. Physiological reviews. 2016; 96:449-547. [PubMed: 26887676]

42. Liu XS, Ardeshirpour L, VanHouten JN, Shane E, Wysolmerski JJ. Site-specific changes in bone microarchitecture, mineralization, and stiffness during lactation and after weaning in mice. J Bone Miner Res. 2012; 27:865-75. [PubMed: 22189918]

43. Vajda EG, Bowman BM, Miller SC. Cancellous and cortical bone mechanical properties and tissue dynamics during pregnancy, lactation, and postlactation in the rat. Biol Reprod. 2001; 65:689-95. [PubMed: 11514329]

44. Alderman BW, Weiss NS, Daling JR, Ure CL, Ballard JH. Reproductive history and postmenopausal risk of hip and forearm fracture. Am J Epidemiol. 1986; 124:262-7. [PubMed: 3728442]

45. Cummings SR, Nevitt MC, Browner WS, et al. Risk factors for hip fracture in white women. Study of Osteoporotic Fractures Research Group. N Engl J Med. 1995; 332:767-73. [PubMed: 7862179]

46. Michaelsson K, Baron JA, Farahmand BY, Ljunghall S. Influence of parity and lactation on hip fracture risk. Am J Epidemiol. 2001; 153:1166-72. [PubMed: 11415951]

47. Chowdhury S, Sarkar NR, Roy SK. Impact of lactational performance on bone mineral density in marginally-nourished Bangladeshi women. Journal of health, population, and nutrition. 2002; 20:26-30.

48. Dursun N, Akin S, Dursun E, Sade I, Korkusuz F. Influence of duration of total breast-feeding on bone mineral density in a Turkish population: does the priority of risk factors differ from society to society? Osteoporosis international: a journal established as result of cooperation between the European Foundation for Osteoporosis and the National Osteoporosis Foundation of the USA. 2006; 17:651-5.

49. Hopkinson JM, Butte NF, Ellis K, Smith EO. Lactation delays postpartum bone mineral accretion and temporarily alters its regional distribution in women. The Journal of nutrition. 2000; 130:77783. [PubMed: 10736329]

50. Laskey MA, Prentice A. Bone mineral changes during and after lactation. Obstetrics and gynecology. 1999; 94:608-15. [PubMed: 10511368]

51. Lissner L, Bengtsson C, Hansson T. Bone mineral content in relation to lactation history in preand postmenopausal women. Calcified tissue international. 1991; 48:319-25. [PubMed: 2054717]

52. More C, Bettembuk P, Bhattoa HP, Balogh A. The effects of pregnancy and lactation on bone mineral density. Osteoporosis international: a journal established as result of cooperation between the European Foundation for Osteoporosis and the National Osteoporosis Foundation of the USA. $2001 ; 12: 732-7$. 
53. Khoo CC, Woo J, Leung PC, Kwok A, Kwok T. Determinants of bone mineral density in older postmenopausal Chinese women. Climacteric. 2011; 14:378-83. [PubMed: 21401441]

54. Rojano-Mejia D, Aguilar-Madrid G, Lopez-Medina G, et al. Risk factors and impact on bone mineral density in postmenopausal Mexican mestizo women. Menopause. 2011; 18:302-6. [PubMed: 20881651]

55. O'Sullivan SM, Grey AB, Singh R, Reid IR. Bisphosphonates in pregnancy and lactationassociated osteoporosis. Osteoporos Int. 2006; 17:1008-12. [PubMed: 16758139]

56. Blanch J, Pacifici R, Chines A. Pregnancy-associated osteoporosis: report of two cases with longterm bone density follow-up. Br J Rheumatol. 1994; 33:269-72. [PubMed: 8156291]

57. Kovacs CS, Ralston SH. Presentation and management of osteoporosis presenting in association with pregnancy or lactation. Osteoporos Int. 2015; 26:2223-41. [PubMed: 25939309]

58. Cohen A, Recker RR, Lappe J, et al. Premenopausal women with idiopathic low-trauma fractures and/or low bone mineral density. Osteoporos Int. 2011 Mar 2. Epub ahead of print.

59. Khosla S, Lufkin EG, Hodgson SF, Fitzpatrick LA, Melton LJ 3rd. Epidemiology and clinical features of osteoporosis in young individuals. Bone. 1994; 15:551-5. [PubMed: 7980966]

60. Moreira Kulak CA, Schussheim DH, McMahon DJ, et al. Osteoporosis and low bone mass in premenopausal and perimenopausal women. Endocr Pract. 2000; 6:296-304. [PubMed: 11242606]

61. Peris P, Guanabens N, Martinez de Osaba MJ, et al. Clinical characteristics and etiologic factors of premenopausal osteoporosis in a group of Spanish women. Semin Arthritis Rheum. 2002; 32:6470. [PubMed: 12219322]

62. Cohen A, Fleischer J, Freeby MJ, McMahon DJ, Irani D, Shane E. Clinical characteristics and medication use among premenopausal women with osteoporosis and low BMD: the experience of an osteoporosis referral center. J Womens Health (Larchmt). 2009; 18:79-84. [PubMed: 19132880]

63. Miller KK, Lee EE, Lawson EA, et al. Determinants of skeletal loss and recovery in anorexia nervosa. J Clin Endocrinol Metab. 2006; 91:2931-7. [PubMed: 16735492]

64. Adams JS, Song CF, Kantorovich V. Rapid recovery of bone mass in hypercalciuric, osteoporotic men treated with hydrochlorothiazide. Ann Intern Med. 1999; 130:658-60. [PubMed: 10215562]

65. Ciacci C, Maurelli L, Klain M, et al. Effects of dietary treatment on bone mineral density in adults with celiac disease: factors predicting response. Am J Gastroenterol. 1997; 92:992-6. [PubMed: 9177517]

66. Mautalen C, Gonzalez D, Mazure R, et al. Effect of treatment on bone mass, mineral metabolism, and body composition in untreated celiac disease patients. Am J Gastroenterol. 1997; 92:313-8. [PubMed: 9040213]

67. McFarlane XA, Bhalla AK, Robertson DA. Effect of a gluten free diet on osteopenia in adults with newly diagnosed coeliac disease. Gut. 1996; 39:180-4. [PubMed: 8991855]

68. Mauro M, Radovic V, Armstrong D. Improvement of lumbar bone mass after infliximab therapy in Crohn's disease patients. Can J Gastroenterol. 2007; 21:637-42. [PubMed: 17948133]

69. Lumachi F, Camozzi V, Ermani M, FDEL, Luisetto G. Bone mineral density improvement after successful parathyroidectomy in pre- and postmenopausal women with primary hyperparathyroidism: a prospective study. Ann N Y Acad Sci. 2007; 1117:357-61. [PubMed: 17646261]

70. Peris P, Ruiz-Esquide V, Monegal A, et al. Idiopathic osteoporosis in premenopausal women. Clinical characteristics and bone remodelling abnormalities. Clin Exp Rheumatol. 2008; 26:98691. [PubMed: 19210860]

71. Wallace BA, Cumming RG. Systematic review of randomized trials of the effect of exercise on bone mass in pre- and postmenopausal women. Calcif Tissue Int. 2000; 67:10-8. [PubMed: 10908406]

72. Ross AC, Manson JE, Abrams SA, et al. The 2011 report on dietary reference intakes for calcium and vitamin D from the Institute of Medicine: what clinicians need to know. J Clin Endocrinol Metab. 2011; 96:53-8. [PubMed: 21118827]

73. Cundy T, Ames R, Horne A, et al. A randomized controlled trial of estrogen replacement therapy in long-term users of depot medroxyprogesterone acetate. J Clin Endocrinol Metab. 2003; 88:7881. [PubMed: 12519833] 
74. Liu SL, Lebrun CM. Effect of oral contraceptives and hormone replacement therapy on bone mineral density in premenopausal and perimenopausal women: a systematic review. Br J Sports Med. 2006; 40:11-24. [PubMed: 16371485]

75. Sagsveen M, Farmer JE, Prentice A, Breeze A. Gonadotrophin-releasing hormone analogues for endometriosis: bone mineral density. Cochrane Database Syst Rev. 2003:CD001297. [PubMed: 14583930]

76. Sim LA, McGovern L, Elamin MB, Swiglo BA, Erwin PJ, Montori VM. Effect on bone health of estrogen preparations in premenopausal women with anorexia nervosa: a systematic review and meta-analyses. Int J Eat Disord. 2010; 43:218-25. [PubMed: 19350651]

77. Lopez LM, Grimes DA, Schulz KF, Curtis KM. Steroidal contraceptives: effect on bone fractures in women. Cochrane Database Syst Rev. 2011:CD006033. [PubMed: 21735401]

78. Wei S, Winzenberg T, Laslett LL, Venn A, Jones G. Oral contraceptive use and bone. Curr Osteoporos Rep. 2011; 9:6-11. [PubMed: 21104044]

79. Cromer BA. Bone mineral density in adolescent and young adult women on injectable or oral contraception. Curr Opin Obstet Gynecol. 2003; 15:353-7. [PubMed: 14501237]

80. Polatti F, Perotti F, Filippa N, Gallina D, Nappi RE. Bone mass and long-term monophasic oral contraceptive treatment in young women. Contraception. 1995; 51:221-4. [PubMed: 7796586]

81. Scholes D, Ichikawa L, LaCroix AZ, et al. Oral contraceptive use and bone density in adolescent and young adult women. Contraception. 2010; 81:35-40. [PubMed: 20004271]

82. Powles TJ, Hickish T, Kanis JA, Tidy A, Ashley S. Effect of tamoxifen on bone mineral density measured by dual-energy $\mathrm{x}$-ray absorptiometry in healthy premenopausal and postmenopausal women. J Clin Oncol. 1996; 14:78-84. [PubMed: 8558225]

83. Vehmanen L, Elomaa I, Blomqvist C, Saarto T. Tamoxifen treatment after adjuvant chemotherapy has opposite effects on bone mineral density in premenopausal patients depending on menstrual status. J Clin Oncol. 2006; 24:675-80. [PubMed: 16446340]

84. Fuleihan Gel H, Salamoun M, Mourad YA, et al. Pamidronate in the prevention of chemotherapyinduced bone loss in premenopausal women with breast cancer: a randomized controlled trial. J Clin Endocrinol Metab. 2005; 90:3209-14. [PubMed: 15769994]

85. Golden NH, Iglesias EA, Jacobson MS, et al. Alendronate for the treatment of osteopenia in anorexia nervosa: a randomized, double-blind, placebo-controlled trial. J Clin Endocrinol Metab. 2005; 90:3179-85. [PubMed: 15784715]

86. Miller KK, Grieco KA, Mulder J, et al. Effects of risedronate on bone density in anorexia nervosa. J Clin Endocrinol Metab. 2004; 89:3903-6. [PubMed: 15292325]

87. Nakayamada S, Okada Y, Saito K, Tanaka Y. Etidronate prevents high dose glucocorticoid induced bone loss in premenopausal individuals with systemic autoimmune diseases. The Journal of rheumatology. 2004; 31:163-6. [PubMed: 14705236]

88. Nzeusseu Toukap A, Depresseux G, Devogelaer JP, Houssiau FA. Oral pamidronate prevents highdose glucocorticoid-induced lumbar spine bone loss in premenopausal connective tissue disease (mainly lupus) patients. Lupus. 2005; 14:517-20. [PubMed: 16130506]

89. Conwell LS, Chang AB. Bisphosphonates for osteoporosis in people with cystic fibrosis. Cochrane Database Syst Rev. 2012; 4:CD002010.

90. Skordis N, Ioannou YS, Kyriakou A, et al. Effect of bisphosphonate treatment on bone mineral density in patients with thalassaemia major. Pediatr Endocrinol Rev. 2008; 6(Suppl 1):144-8. [PubMed: 19337169]

91. Okada Y, Nawata M, Nakayamada S, Saito K, Tanaka Y. Alendronate protects premenopausal women from bone loss and fracture associated with high-dose glucocorticoid therapy. The Journal of rheumatology. 2008; 35:2249-54. [PubMed: 19031508]

92. Yeap SS, Fauzi AR, Kong NC, et al. A comparison of calcium, calcitriol, and alendronate in corticosteroid-treated premenopausal patients with systemic lupus erythematosus. The Journal of rheumatology. 2008; 35:2344-7. [PubMed: 19004038]

93. Minsker DH, Manson JM, Peter CP. Effects of the bisphosphonate, alendronate, on parturition in the rat. Toxicol Appl Pharmacol. 1993; 121:217-23. [PubMed: 8346538]

94. Levy S, Fayez I, Taguchi N, et al. Pregnancy outcome following in utero exposure to bisphosphonates. Bone. 2009; 44:428-30. [PubMed: 19059370] 
95. Ornoy A, Wajnberg R, Diav-Citrin O. The outcome of pregnancy following pre-pregnancy or early pregnancy alendronate treatment. Reprod Toxicol. 2006; 22:578-9. [PubMed: 16996245]

96. Munns CF, Rauch F, Ward L, Glorieux FH. Maternal and fetal outcome after long-term pamidronate treatment before conception: a report of two cases. J Bone Miner Res. 2004; 19:1742-5. [PubMed: 15355570]

97. Khosla S, Burr D, Cauley J, et al. Bisphosphonate-associated osteonecrosis of the jaw: report of a task force of the American Society for Bone and Mineral Research. J Bone Miner Res. 2007; 22:1479-91. [PubMed: 17663640]

98. Shane E, Burr D, Ebeling PR, et al. Atypical subtrochanteric and diaphyseal femoral fractures: report of a task force of the American Society for Bone and Mineral Research. J Bone Miner Res. 2010; 25:2267-94. [PubMed: 20842676]

99. Finkelstein JS, Klibanski A, Arnold AL, Toth TL, Hornstein MD, Neer RM. Prevention of estrogen deficiency-related bone loss with human parathyroid hormone-(1-34): a randomized controlled trial. Jama. 1998; 280:1067-73. [PubMed: 9757854]

100. Langdahl BL, Marin F, Shane E, et al. Teriparatide versus alendronate for treating glucocorticoidinduced osteoporosis: an analysis by gender and menopausal status. Osteoporos Int. 2009; 20:2095-104. [PubMed: 19350340]

101. Saag KG, Shane E, Boonen S, et al. Teriparatide or alendronate in glucocorticoid-induced osteoporosis. N Engl J Med. 2007; 357:2028-39. [PubMed: 18003959]

102. Cohen A, Stein EM, Recker RR, et al. Teriparatide for idiopathic osteoporosis in premenopausal women: a pilot study. J Clin Endocrinol Metab. 2013; 98:1971-81. [PubMed: 23543660]

103. Nishiyama KK, Cohen A, Young P, et al. Teriparatide increases strength of the peripheral skeleton in premenopausal women with idiopathic osteoporosis: a pilot HR-pQCT study. J Clin Endocrinol Metab. 2014; 99:2418-25. [PubMed: 24684466]

104. Fazeli PK, Wang IS, Miller KK, et al. Teriparatide increases bone formation and bone mineral density in adult women with anorexia nervosa. J Clin Endocrinol Metab. 2014; 99:1322-9. [PubMed: 24456286]

105. Choe EY, Song JE, Park KH, et al. Effect of teriparatide on pregnancy and lactation-associated osteoporosis with multiple vertebral fractures. Journal of bone and mineral metabolism. 2012; 30:596-601. [PubMed: 22105654]

106. Finkelstein JS, Arnold AL. Increases in bone mineral density after discontinuation of daily human parathyroid hormone and gonadotropin-releasing hormone analog administration in women with endometriosis. J Clin Endocrinol Metab. 1999; 84:1214-9. [PubMed: 10199756]

107. Cohen A, Kamanda-Kosseh M, Recker RR, et al. Bone Density After Teriparatide Discontinuation in Premenopausal Idiopathic Osteoporosis. J Clin Endocrinol Metab. 2015; 100:4208-14. [PubMed: 26358172]

108. Peris P, Monegal A, Martinez MA, Moll C, Pons F, Guanabens N. Bone mineral density evolution in young premenopausal women with idiopathic osteoporosis. Clin Rheumatol. 2007; 26:958-61. [PubMed: 16941198]

109. Cohen, A., Young, P., Stein, EM., et al. Absence of the anabolic window characterizes premenopausal women with idiopathic osteoporosis who do not respond to teriparatide. American Society for Bone and Mineral Research Annual Meeting; 2012; p. 2012

110. Cohen, A., Stein, EM., Dempster, D., et al. Premenopausal Women with Idiopathic Osteoporosis, Baseline Bone Turnover Predicts Response to Teriparatide. American Society for Bone and Mineral Research; 2011; San Diego, CA. 2011.

111. Kaunitz AM, Miller PD, Rice VM, Ross D, McClung MR. Bone mineral density in women aged 25-35 years receiving depot medroxyprogesterone acetate: recovery following discontinuation. Contraception. 2006; 74:90-9. [PubMed: 16860045]

112. Scholes D, LaCroix AZ, Ichikawa LE, Barlow WE, Ott SM. Change in bone mineral density among adolescent women using and discontinuing depot medroxyprogesterone acetate contraception. Arch Pediatr Adolesc Med. 2005; 159:139-44. [PubMed: 15699307]

113. Adachi JD, Bensen WG, Brown J, et al. Intermittent etidronate therapy to prevent corticosteroidinduced osteoporosis. N Engl J Med. 1997; 337:382-7. [PubMed: 9241127] 
114. Saag KG, Emkey R, Schnitzer TJ, et al. Alendronate for the prevention and treatment of glucocorticoid-induced osteoporosis. Glucocorticoid-Induced Osteoporosis Intervention Study Group. N Engl J Med. 1998; 339:292-9. [PubMed: 9682041]

115. Wallach S, Cohen S, Reid DM, et al. Effects of risedronate treatment on bone density and vertebral fracture in patients on corticosteroid therapy. Calcif Tissue Int. 2000; 67:277-85. [PubMed: 11000340]

116. Grossman JM, Gordon R, Ranganath VK, et al. American College of Rheumatology 2010 recommendations for the prevention and treatment of glucocorticoid-induced osteoporosis. Arthritis Care Res (Hoboken). 62:1515-26. [PubMed: 20662044] 


\section{KEY POINTS}

- $\quad$ Premenopausal fractures are rare, and may be an important indicator of underlying poor bone quality and future fracture risk.

- Measurement of BMD by DXA should not be used as the sole guide for diagnosis or treatment of osteoporosis in premenopausal women.

- $\quad$ Timing of peak BMD accrual and expected changes associated with pregnancy and lactation should be considered when interpreting BMD results obtained in premenopausal women.

- Evaluation of low trauma fractures or low BMD should include a thorough evaluation for potential secondary causes.

- Where possible, treatment of the underlying cause should be the focus of management. 